\title{
REGRESSÃO MÚLTIPLA PARA ESTIMATIVA ESPACIAL DA PRODUTIVIDADE DE CAFÉ ARÁBICA UTILIZANDO ATRIBUTOS FOLIARES
}

\author{
Jorge Tadeu Fim Rosas ${ }^{1}$ \\ Vinícius Agnolette Capelini ${ }^{2}$ \\ Samira Luns Hatum de Almeida ${ }^{3}$ \\ Gabriel Dias de Oliveira ${ }^{4}$ \\ Julião Soares de Souza Lima ${ }^{5}$ \\ Samuel de Assis Silva ${ }^{6}$
}

Resumo: O objetivo deste trabalho foi estimar a produtividade de café com base em nutrientes foliares, utilizando regressão múltipla. O experimento foi conduzido em uma lavoura comercial de Coffea arabica $L$., variedade catucaí. Para a coleta das amostras de produção e de folha, foi montada uma malha amostral de 100 pontos em toda a lavoura. Dos onze atributos analisados apenas cinco apresentaram significância quanto a suas presenças nos tecidos foliares associados a produtividade ao nível de $5 \%$ de probabilidade. Somente esses atributos foram utilizados para compor o modelo linear. Os valores de produtividade apresentaram dependência espacial, com variogramas com patamares bem definidos. Foi possível estimar a produtividade a partir de cinco nutrientes presentes nas folhas. A produtividade estimada pela regressão múltipla minimizou a variabilidade espacial da produtividade. Os valores de produtividade estimada foram bem próximos ao real, o que torna o uso de modelos de regressão múltipla uma técnica aplicável à agricultura de precisão.

Palavras-chave: Agricultura de Precisão; Geoestatística; Nutrição mineral de plantas.

\footnotetext{
1 Departamento de Engenharia Rural/Universidade Federal do Espírito Santo, Brasil, E-mail: jorgetadeufimrosas@hotmail.com.

2 Departamento de Engenharia Rural/Universidade Federal do Espírito Santo, Brasil, E-mail: vinicius91ac@hotmail.com.

3 Departamento de Engenharia Rural/Universidade Federal do Espírito Santo, Brasil, E-mail: samiraluns@hotmail.com.

4 Departamento de Engenharia Rural/Universidade Federal do Espírito Santo, Brasil, E-mail: gabriel.dias.oliveira@gmail.com.

5 Departamento de Engenharia Rural/Universidade Federal do Espírito Santo, Brasil E-mail: limajss@yahoo.com.br.

${ }^{6}$ Departamento de Engenharia Rural/Universidade Federal do Espírito Santo, Brasil, E-mail: sasilva@pq.cnpq.br.
} 